\title{
Regulation of ES Cell Self Renewal and Pluripotency by Foxd3
}

\author{
Ying Liu ${ }^{1}$ and Patricia A. Labosky ${ }^{*}$ \\ Center for Stem Cell Biology Department of Cell and Developmental Biology 2213 Garland Ave \\ 9465 MRB IV Vanderbilt University School of Medicine Nashville, TN 37232-0494, USA
}

\section{Abstract}

The Foxd3 forkhead transcription factor is required for maintaining pluripotent cells in the early mouse embryo and for the establishment of murine embryonic stem (ES) cell lines. To begin to understand the role of Foxd3 in ES cell maintenance, we derived ES cell lines from blastocysts that carried two conditional Foxd 3 alleles and a tamoxifen-inducible Cre transgene. Tamoxifen treatment produced a rapid and near complete loss of Foxd3 mRNA and protein. Foxd3-deficient ES cells maintained a normal proliferation rate but displayed increased apoptosis, and clonally dispersed ES cells showed a decreased ability to self-renew. Under either self-renewal or differentiation-promoting culture conditions we observed a strong, precocious differentiation of Foxd3 mutant ES cells along multiple lineages including trophectoderm, endoderm and mesendoderm. This profound alteration in biological behavior occurred in the face of continued expression of factors known to induce pluripotency including Oct4, Sox 2 and Nanog. We present a model for the role of Foxd3 in repressing differentiation, promoting self-renewal and maintaining survival of mouse ES cells.

\section{Keywords}

Foxd3; ES cell; self-renewal; transcription factor

\section{INTRODUCTION}

Murine embryonic stem cells (ES cells) are derived from the inner cell mass (ICM) of blastocyst stage embryos and can be maintained indefinitely in vitro while retaining the ability to subsequently differentiate into all the cells of the adult animal. Understanding properties of ES cells and how self-renewal and pluripotency are regulated will have a large impact on developmental biology studies and regenerative medicine. Several transcription factors are required for ES cell self-renewal and pluripotency, including Oct4, Sox2 and Nanog, and inactivation of these genes leads to loss of pluripotent stem cells and aberrant differentiation into extraembryonic trophoblast in the case of Oct 4 and Sox2, or primitive endoderm in the case of Nanog ${ }^{1-5}$. Recently, overexpression of a cocktail of transcription factors (Oct4, Sox2, c-Myc and Klf4 or Oct4, Sox2, Lin-28 and Nanog) has resulted in the induction of pluripotency in somatic cells $6-10$. These "induced pluripotent stem cells" (iPSCs) have all the properties of ES cells, but the mechanism of this induction is still unclear. Identification of factors immediately downstream of these transcription factors will be crucial.

\footnotetext{
*Author for correspondence, trish.labosky@ vanderbilt.edu Phone 615-322-2540, Fax 615-322-6645

${ }^{1}$ Present address: Cell \& Developmental Biology, College of Life Sciences, University of Dundee, UK Author Contribution:

Ying Liu: Collection and assembly of data, data analysis and interpretation, manuscript writing.

Patricia Labosky: Conception and design, financial support, collection and assembly of data, data analysis and interpretation, manuscript writing.
} 
Foxd3 is a forkhead transcription factor required for maintenance of progenitor cells in the ICM, trophoblast and neural crest lineages $11-13$. Foxd $3^{-/-}$embryos die shortly after implantation and cells in the mutant ICM and epiblast undergo extensive programmed cell death ${ }^{11}$. ES cells express Foxd3 and expression is dramatically downregulated when cells are induced to differentiate ${ }^{14}$, suggesting that Foxd3 expression in pluripotent stem cells is functionally significant. Together, this work illustrates the important role Foxd3 plays to maintain multipotent progenitor cells from divergent embryonic lineages, but the early lethality of Foxd $3^{-/-}$embryos and therefore inability to establish Foxd3 $3^{-/}$ES cell lines, hampered efforts to study the role Foxd3 plays in ES cell maintenance.

To circumvent this problem, we derived ES cell lines in which Cre-mediated inactivation of Foxd3 function can be temporally regulated. These $F$ oxd $3^{f l f l} ; C A G G C r e-E R^{T M}$

$\left(\right.$ Foxd $3^{f l f l}$;Cre-ER) ES cells are indistinguishable from normal ES cells in culture, and the Foxd3 coding region is deleted when cells are cultured in the presence of 4-hydroxytamoxifen (TM). Using this inducible system, we demonstrate that Foxd3 is not required for cell proliferation, but that mutant ES cells undergo increased apoptosis indicating Foxd3 is required for ES cell survival. Mutant ES cells were defective in their ability to form colonies from single cells, illustrating a requirement for Foxd3 in stem cell self-renewal. At the same time, while maintained under differentiation inhibiting conditions, Foxd3 mutant ES cells do not respond to these cues and undergo extensive differentiation despite the maintenance of expression of multiple stem cell genes. Together, our results shape a deeper understanding of the biological roles of this transcription factor in murine ES cells and allow us to propose a model that will further our comprehension of mechanisms regulating maintenance of self-renewal and multipotency, the defining characteristics of all stem cells.

\section{MATERIALS AND METHODS}

\section{Generation of Inducible Foxd3 Mutant mES Cell Lines}

Foxd $3^{f l}$ mice were maintained on a $129 \mathrm{~S} 6 / \mathrm{SvEvTac}$ (Taconic) genetic background ${ }^{13}$. Mice carrying a tamoxifen-inducible variant of Cre recombinase $\left(C A G G C r e-E R^{T M}\right.$, also called $\mathrm{Tg}$ (cre/Esr1)5Amc) ${ }^{15}$ (The Jackson Laboratory) were backcrossed four times to $129 \mathrm{~S} 6 / \mathrm{SvEvTac}$ mice. The resulting animals were crossed to Foxd $3^{f l f f l}$ mice and a line of $F o x d 3^{f l l f l} ; C A G G C r e-$ $E R^{T M}$ established. These were interbred and blastocysts harvested at $3.5 \mathrm{dpc}$ using standard methods 16,17 . Blastocysts were cultured on irradiated STO fibroblasts in ES cell medium supplemented with 50 $\mathrm{MM}$ MEK1 inhibitor PD98059 (Cell Signaling Technology). After 3-4 days, ICM outgrowths were isolated, trypsinized in microdrops, and cell suspensions transferred to fresh feeder layers. After 4-5 days, ES cell lines were obvious in the cultures. Lines were cryopreserved at passage number 3-4 and samples were lysed for DNA extraction. Individual cell lines were gentoyped for the $F o x d 3^{f l}$ allele and presence of $\mathrm{Cre}$ using PCR as described ${ }^{13}$. Animal care was in accordance with Vanderbilt University IACUC guidelines.

\section{ES Cell Culture}

ES cells were cultured on irradiated mouse embryonic fibroblast (MEF) feeder cells using standard protocols ${ }^{17}$. 4-hydroxytamoxifen (Sigma) was dissolved in ethanol at $1 \mathrm{mM}$ stock concentration, and added to the medium on a daily basis at the concentration of $2 \mu \mathrm{M}$ unless otherwise specified. Differentiation of ES cells was carried out by generating embryoid bodies (EBs) in suspension culture on ultra-low attachment dishes (Corning) in ES medium without addition of LIF.

\section{Cell Number Analysis and Self-Renewal Assay}

For cell number analysis, ES cells were plated at a density of $5 \times 10^{4}$ cells/well in 12-well dishes. Two to four days after plating, cells were dissociated with trypsin and triteration to a single 
cell suspension and manually counted with a hemocytometer. Cell numbers were measured for multiple cell lines from at least three independent experiments.

To assay for self-renewal, ES cells treated with or without $2 \mu \mathrm{M}$ TM for two days were dissociated and plated at clonal density $\left(10 \mathrm{cell} / \mathrm{s} / \mathrm{cm}^{2}\right)$ on MEF feeders in 12 -well dishes. At day 4, cells were fixed and stained for alkaline phosphatase activity according to manufacturer's instruction (Millipore) and counter-stained with 4,6-diamidino-2-phynylindole (DAPI). Colony formation efficiency was calculated by the counting the number of AP-positive colonies divided by the total number of cells plated. Number of cells per colony was determined by manually counting DAPI-stained cells. Positively stained cells were manually counted by two individuals who were blinded to the genotypes and TM treatment. Colony formation efficiency and number of cells/colony were determined from three independent experiments.

\section{Immunocytochemistry}

ES cells were washed with phosphate-buffered saline (PBS), and fixed with $4 \%$

paraformaldehyde (PFA) in PBS for 30 minutes at room temperature. EBs were washed with PBS, and fixed with $4 \%$ PFA at $4{ }^{\circ} \mathrm{C}$ for 1 hour. After sinking in $30 \%$ sucrose at $4{ }^{\circ} \mathrm{C}$ overnight, EBs were embedded in OCT, and cryosectioned at $10 \mu \mathrm{m}$. For immunofluorescence, cells or sections were permeabilized and blocked using $0.1 \%$ Triton X-100 (Sigma) and 1\% goat serum (Jackson ImmunoResearch) in PBS. Primary antibodies were diluted in blocking buffer and incubated overnight at $4{ }^{\circ} \mathrm{C}$. Secondary antibodies diluted in blocking buffer were incubated at room temperature for 1 hour. Cells were counter-stained with DAPI. Images were captured using a Zeiss Observer A.1 fluorescent microscope and AxioCam MRc5 camera. Cells were counted manually by two individuals.

Primary antibodies used include: rabbit anti-Foxd $3^{12}$ (1:1000), rabbit anti-phospho-Histone 3 (pH3, 1:500; Millipore), mouse anti-Oct4 (1:500; Beckton Dickinson), rabbit anti-Sox2 (1:3000; kind gift from Dr. Larysa Pevny), rabbit anti-Nanog (1:500; Invitrogen), mouse antiFoxa2 (1:50; Developmental Studies Hybridoma Bank), rabbit anti-Foxa2 (1:500; kind gift from Dr. Chin Chiang). Secondary antibodies used were Cy3 (Jackson ImmunoResearch) and Alexa 488 (Invitrogen) goat anti-rabbit or goat anti-mouse (1:500).

\section{Proliferation and TUNEL Assays}

$500 \mu \mathrm{g} / \mathrm{ml}$ of 5-bromo-2'-deoxyuridine (BrdU; Sigma) was added to the culture medium for one hour. Cells were then fixed with 4\% PFA in PBS, washed with PBS, and treated with $2 \mathrm{~N}$ $\mathrm{HCl}$ for $20 \mathrm{~min}$. Immunocytochemistry was performed as described above using a mouse antiBrdU (1:50; Beckton Dickinson) antibody. TUNEL assays were performed using the In Situ Cell Death Detection Kit (Roche) according to manufacturer's instructions. BrdU-positive, pH3-positive and TUNEL-positive cells were counted and the percentages calculated against total number of DAPI-stained cells. Data were collected from more than 3 independent experiments with more than 7000 DAPI-positive cells counted for each treatment.

\section{RNA Isolation and RT-PCR}

Total RNA was isolated using the RNeasy Mini Kit or RNeasy Micro Kit (Qiagen) followed by TURBO DNase treatment (Ambion) according to manufacturer's instructions. cDNA synthesis was carried out with 500ng of total RNA using SuperScript III qRT-PCR kit (Invitrogen). Real-time quantitative RT-PCR (qRT-PCR) was performed with ABI PRISM 7900 Sequence Detection System using SYBR Green Master Mix (ABI). Samples were run in duplicate and relative levels of each mRNA were examined by comparing Cycle Threshold $(\mathrm{Ct})$ values for each reaction among samples using the Hypoxanthine phosphoribosyl transferase (Hprt) gene as reference. Relative expression levels of each mRNA were measured 
from at least 3 independent experiments, and compared by Student's t-test. Primer sequences are listed in Supplemental Table 1.

\section{RESULTS}

\section{Reduction of Foxd3 Expression by 4-Hydroxytamoxifen Treatment}

Foxd3 is required for maintenance of the ICM and the establishment of ES cell lines ${ }^{11}$. Therefore, in order to generate a genetic lesion of Foxd3 in ES cells, we needed to develop a regulatable system. The Foxd 3 conditional allele $\left(F o x d 3^{f l}\right)^{13}$ was designed so that Cremediated recombination deletes the entire coding region of Foxd3 gene. The CAGG Cre$E R^{T M}$ transgenic line expresses a tamoxifen-regulated fusion protein of Cre fused to a modified ligand binding domain of the estrogen receptor (ER) ${ }^{15}$. Foxd $3^{f l f l} ; C A G G C r e-E R^{T M}$ $\left(F o x d 3^{f l f l}\right.$;Cre-ER) mice appeared normal and healthy and were intercrossed to obtain blastocysts for ES cell derivation. We obtained experimental lines $\left(F o x d 3^{f l f l} ; \mathrm{Cre}-E R\right)$ and control lines without the $\mathrm{Cre}$-ER transgene $\left(F o x d 3^{f l f l}\right)$ in equal numbers. Genotyping scheme is show in Fig. 1A. PCR of genomic DNA isolated from wild type, Foxd $3^{f l f l} ;$ Cre-ER and Foxd $3^{f l f l}$ ES cells confirmed the lack of wild type and presence of $F o x d 3^{f l}$ alleles in untreated Foxd $3^{f l f l}$;Cre-ER and Foxd $3^{f l f l}$ cells, and the presence of the Cre transgene in Foxd $3^{f l / f l}$;Cre$E R$ cells (Fig. 1B). When cultured in complete ES cell medium without TM, ES cells of both genotypes appeared similar to wild type ES cells and displayed comparable growth rates. When TM was added to the culture medium, the presence and intensity of the PCR product from the Foxd $3^{f l}$ allele was unchanged in Foxd $3^{f l f l}$ control ES cells. However, recombination of the Foxd $3^{f l}$ allele was detected in TM-treated Foxd $3^{f l f f l}$;Cre-ER experimental cells (Fig. 1B). Cremediated recombination was not complete because some Foxd $3^{f l}$ PCR product was detected in the TM treated cultures (Fig. 1B). Real-time quantitative PCR revealed that after 3 days of TM treatment, the PCR signal from the Foxd $3^{f l}$ allele in TM-treated Foxd $3{ }^{f l f l}$; $C r e$-ER cultures ranged from 13 to $24 \%$ of levels in untreated ES cells ( $\mathrm{n}=3$ experiments, data not shown).

We analyzed four independent cell lines of each genotype for Foxd 3 expression at the mRNA and protein levels; E1, E2, E3 and E4 were experimental lines and C1, C2, C3, and C4 were control lines. Immunocytochemistry with a Foxd3 antibody revealed that $70-90 \%$ of the ES cells in untreated cultures expressed Foxd3 (Fig. 1E), consistent with the expression of Foxd3 in the $\mathrm{ICM}^{11}$. However, when cultured in the presence of TM, Foxd 3 mRNA and protein levels were significantly reduced in experimental cells but not control cells (Fig. 1C, D; see also Fig. $3 \mathrm{~A}$ and C). Real time quantitative RT-PCR (qRT-PCR) analysis revealed a greater than $90 \%$ reduction of Foxd3 mRNA in Foxd $3^{\text {fllfl }}$;Cre-ER ES cells one day after TM treatment and after 2 days mRNA levels were nearly undetectable (Fig. 1D). Quantification of the number of Foxd3 expressing cells by immunocytochemistry showed that after one day of TM treatment, about $15 \%$ of the cells still contained Foxd3 protein (Fig. 1E, arrowheads). Two and three days of TM treatment resulted in further reduction of Foxd3-positive cells in the cultures $(7.4 \%$ and $5.8 \%$ respectively) and a decrease in total Foxd3 protein as measure by western blot analysis (data not shown), suggesting that Cre-mediated recombination occurred in the vast majority of cells under these conditions.

\section{Foxd3 is Required for ES Cell Self-renewal and Survival}

To examine whether Foxd3 plays a role in growth and maintenance of ES cells, we quantified the effect of TM treatment on cell numbers in experimental and control ES cells. When Foxd $3^{f l f l}$; Cre-ER ES cells were cultured in the presence of $2 \mu \mathrm{M}$ TM, the number of surviving cells after 2-4 days was significantly reduced compared to control cultures (Fig. 2A). Control Foxd $3^{f l f l}$ ES cells cultured in the absence or presence of $2 \mu \mathrm{M}$ TM had a similar number of surviving cells after 2-4 days of TM treatment (Fig. 2A). These results suggest that loss of Foxd3, but not treatment with TM, was responsible for the decreased cell numbers and colony 
size (Supplemental Fig. 1A) in ES cells. A higher concentration of TM $(4 \mu \mathrm{M})$ showed a nonspecific toxic effect, control cell lines cultured in the presence of $4 \mu \mathrm{M}$ TM had reduced number of cells (Fig. 2A). Therefore, we used $2 \mu \mathrm{M}$ TM for the rest of our experiments. Serial passaging of Foxd $3^{f l f f l}$; Cre-ER ES cells with TM treatment (ten passages) resulted in decreased number of surviving cells at each passage; however, cells did not die off and continued culture was possible in most cases (Supplemental Fig. 1B). However, many of these cells were Foxd3positive, suggesting that they were selectively able to proliferate despite continued TM in the medium (data not shown).

Self-renewal of stem cells is defined by the ability of a single cell to give rise to a new colony of stem cells ${ }^{18-20}$. Cells were cultured with or without TM for 2 days and plated at clonal density $\left(10\right.$ cells $\left./ \mathrm{cm}^{2}\right)$. Alkaline phosphatase (AP) staining was performed after 4 days and immunocytochemistry confirmed that the mutant AP-positive colonies no longer expressed Foxd3 (Fig. 2B). The efficiency of colony formation of untreated experimental cells was $44.4 \%$, while TM-treated cells formed colonies at only $10.6 \%$ (Fig. 2C), suggesting a defect in self-renewal of Foxd3-deficient ES cells. In addition, although both untreated and $2 \mu \mathrm{M}$ TMtreated cultures of Foxd $3^{f l f l}$; Cre-ER ES cell lines contained AP-positive colonies (Fig. 2B), treated colonies contained 3-4 fold fewer cells than control colonies (Fig 2D). When the same assays were performed with Foxd $3^{f l f l}$ control ES cells, we saw no difference in either colony size or efficiency of colony formation with (42.7\%) or without (45.6\%) TM treatment (Supplemental Fig. 1C and D). These experiments demonstrate that Foxd3 is required for selfrenewal of ES cells.

The reduced cell numbers and colony size we observe in ES cell cultures could be caused by increased cell death and/or decreased cell proliferation. We measured programmed cell death by TUNEL labeling, and while control cultures without TM treatment exhibited few apoptotic cells, we observed more $F o x d 3^{f l f f l} ; \mathrm{Cre}$-ER ES cells treated with TM undergoing apoptosis at 2 and 3 days after TM treatment compared to controls (Fig. 3A, arrows). Quantification of the percent of TUNEL-positive cells showed a two-fold increase in apoptosis after 2 or 3 days of TM treatment (Fig. 3B). There was no increase of apoptosis in Foxd $3^{f l / f l}$ control ES cells treated with TM (Fig. 3A). These data indicate that Foxd3 plays an important role in maintaining ES cell survival. In mutant colonies, Foxd3 positive ES cells (Fig. 3A, arrowheads) and TUNEL positive cells (Fig. 3A, arrows) were observed, but Foxd3/TUNEL-double positive cells were rarely seen ( 2 out of 972 cells counted at day 2 and 3/1034 for day 3), suggesting a cellautonomous function of Foxd 3 in preventing ES cells from programmed cell death. To examine proliferation of Foxd 3 mutant cells, we used BrdU incorporation to identify cells in S phase of the cell cycle, and phospho-Histone 3 (pH3) as a marker for cells in G2-M phase. In mutant cultures, many Foxd3-deficient ES cells were BrdU-positive (Fig. 3C, arrows), suggesting that Foxd3 is not required for ES cells to enter S phase of the cell cycle. Quantification of BrdUpositive cells showed no significant difference between mutant and control cultures (Fig. 3D). Similarly, the percent of pH3-positive cells in Foxd3 mutant ES cell cultures was similar to that of untreated cultures (Fig. 3E and F). Together, these data show that the deletion of Foxd3 has no significant effect on ES cell proliferation, but results in increased cell death.

\section{Maintenance of Stem Cell Gene Expression in Foxd3 Mutant ES Cells}

Pluripotent ES cells are maintained in an undifferentiated state by the function of a set of key transcription factors including Oct4, Sox2 and Nanog 21,22 , and overexpression of these transcription factors in combination with Klf4, c-Myc and/or Lin28 can reprogram somatic cells to adopt a stem cell phenotype ${ }^{7-10,23}$. To examine whether the loss of Foxd3 affects the expression of these stem cell genes, we analyzed mRNA levels and protein expression of multiple stem cell transcription factors in Foxd 3 mutant ES cells. Immunocytochemistry for Oct4, Sox 2 and Nanog showed that all three proteins were expressed in Foxd3 mutant ES cells 
after 3 days of TM treatment (Fig. 4A). Double immunocytochemistry for Oct4 and Foxd3 confirmed that most Oct4-positive cells in mutant cultures were Foxd3-deficient (Fig. 4A), suggesting that Foxd3 is not required for maintaining the expression of these stem cell genes. A time-course analysis of mRNA levels for these genes along with Zfx, Esrrb, $c-M y c, T b x 3$ and Klf4 by qRT-PCR revealed a small decrease of transcript levels of some of the genes after days 1 and 2 of TM treatment, and by day 3, expression levels were either unchanged or slightly increased (Fig. 4B). Oct4 protein levels in the treated experimental cultures were also maintained as measured by western blotting (data not shown). These findings indicate that Foxd 3 is not required to maintain the expression of the stem cell genes analyzed, and suggest that Foxd3 may function downstream of these genes, or in a parallel pathway, in mouse ES cells.

\section{Aberrant Differentiation of Foxd3 Mutant ES Cells}

When ES cells are cultured in the presence of mitotically inactivated embryonic fibroblast feeders, serum and LIF, the overwhelming majority of the cells maintain an undifferentiated phenotype. To examine the differentiation status of Foxd 3 mutant ES cells cultured under conditions that normally inhibit differentiation, we used qRT-PCR to monitor expression of differentiation markers for several lineages. A 2-4 fold increase in mRNA levels of primitive endoderm markers Foxa2, AFP and Sox 17 in TM treated cultures was observed (Fig. 5A), indicating increased differentiation to primitive endoderm of Foxd3-deficient ES cells. Trophectoderm is an extra-embryonic lineage that contributes to the placenta, and normally ES cells do not contribute to trophectoderm in chimeras or in vitro ${ }^{24}$. Despite this lineage restriction, Foxd3 mutant ES cells showed a 12-, 3.4- and 4.4-fold increase in mRNAs for trophectoderm markers $C d x 2, F g f r 2$ and $C s h 1 / P L 1$, respectively (Fig. 5B). After implantation, the ICM gives rise to primitive ectoderm/epiblast cells, which then contribute to cells in the three primary germ layers. One of the first differentiation markers expressed in epiblast cells in vivo, Fgf5 25 , was increased 2-fold in Foxd 3 mutant ES cells (Fig. 5C). Goosecoid (Gsc) and Brachyury $(T)$, molecular markers for mesendoderm ${ }^{26}$, increased 5.4- and 12-fold, respectively (Fig. 5C). Together, these results suggest that Foxd3 normally functions to maintain ES cells in an undifferentiated state by repressing differentiation towards extraembryonic and embryonic lineages. Interestingly, expression levels of neuroectoderm markers Nestin, Pax6 and Soxl either decreased or remained the same in mutant cells (Fig. 5D), suggesting that Foxd3 selectively represses commitment of epiblast cells into mesoderm and endoderm lineages, but not ectoderm.

During lineage diversification ES cells up-regulate lineage-specific genes while downregulating self-renewal genes. One possible mechanism for precocious and aberrant differentiation is the disruption of this coordinated regulation, with the induction of lineage specific gene networks at the same time that self-renewal gene expression is maintained. To test this possibility in Foxd3 mutant ES cells, we performed double immunocytochemistry for the endoderm marker Foxa2 and stem cell markers Oct4 and Sox2 (Fig. 5E). Both TM-treated Foxd $3^{f l f l}$; Cre-ER cultures (Fig. 5E) and untreated cultures (data not shown) contained very few cells that were double-positive for Foxa2 and Oct4 or Sox2 (Fig. 5E, arrowheads; 4-5\% cells in both mutant and control cultures), suggesting the coordination between differentiation and self-renewal was not disrupted in Foxd3 mutant ES cells. Surprisingly, the percent of Oct4positive and Foxa2-positive cells in control and mutant cultures were similar (Fig. 5F). Because we observed increased apoptosis in Foxd3 mutant cultures, we performed TUNEL analysis and immunolocalization for either Oct4 or Foxa2 to examine which population of cells preferentially undergoes apoptosis. Oct 4 cells are mostly in the internal portion of the colonies while Foxa2 cells are at the periphery (Fig 5E and G). In control cultures, TUNEL/Oct 4 doublepositive cells were rarely observed (Fig. $5 \mathrm{H} ; 1.5 \%$ of total Oct4-positive cells); in mutant cultures, the percentage of TUNEL/Oct4 double-positive cells was similar (Fig. 5G and H; 
$2 \%$ ). In contrast, we measured 6.6\% TUNEL/Foxa2 double-positive cells in control cultures versus a significantly higher $28.7 \%$ TUNEL/Foxa2 double-positive cells in mutant cultures (Fig. 5G and H). Furthermore, in mutant cultures, not only did we observe TUNEL/Foxa2 double-positive cells that were DAPI-positive (Fig. 5G, arrowheads), we also observed many cells at the edge of colonies that were TUNEL/Foxa2 double-positive but DAPI-negative, suggesting these cells have lost their nuclear integrity (Fig. 5G, arrows). Together, these data indicate that Foxd 3 mutant ES cells undergo aberrant differentiation, and these differentiated cells have a higher tendency for apoptosis.

\section{Precocious Differentiation of Foxd3 Mutant Embryoid Bodies}

ES cells not only have the capacity to self-renew in vitro, they are also capable of differentiating into multiple cell types. When ES cells are grown in suspension culture without LIF, the cells aggregate to form embryoid bodies (EBs). EBs differentiate in a manner similar to the early $\mathrm{ICM}^{27-29}$. First, cells in the outer layer of the EBs differentiate to primitive endoderm that forms a thick basement membrane separating the primitive endoderm layer from the inner core of the $\mathrm{EBs}^{27}$. Next, EBs undergo cavitation similar to formation of the proamniotic cavity in the embryo ${ }^{30}$. Cells in the inner core resemble epiblast/primitive ectoderm, and undergo differentiation into cells from all three germ layers.

Foxd $3^{f l f l}$; Cre-ER ES cells formed EBs when cultured in the presence of $2 \mu \mathrm{M}$ TM. However, the EBs were much smaller than those from cells without TM treatment (Supplemental Fig. 2A), consistent with reduced cell survival in the absence of Foxd3. QRT-PCR confirmed that Foxd3 mRNA was decreased in TM-treated cells in day 2 to day 8 EBs (Supplemental Fig. 2B and C). We examined primitive endoderm differentiation by qRT-PCR analysis of Foxa 2 mRNA levels in control and mutant EBs, and observed increased Foxa 2 expression in Foxd3 mutant EBs at all stages examined (Fig. 6A). In control D4 EBs, Foxa2 protein was detected primarily in the outer layer of primitive endoderm cells (Fig. 6B). In contrast, mutant EBs contained more Foxa2-positive cells, with many located within the core of the EBs. By D8, in addition to the outer layer Foxa2-positive primitive endoderm cells, a few Foxa2positive cells were observed in the inner core of control EBs. The Foxa2-positive cells in Foxd3 mutant EBs were more numerous and widespread in the inside of the EBs (Fig. 6B). Comparing the percent of Foxa2-positive cells in control and mutant EBs, we found a 5-fold and 3-fold increase in mutant EBs at D4 and D8, respectively (Fig. 6C). QRT-PCR analysis showed increased expression of another early endoderm marker, Sox17, in mutant EBs (Fig. 6D). mRNA levels of Foxa2 and Sox17 in mutant D2-D8 EBs were 3-fold to 18-fold higher than those in control EBs (Fig. 6A and 6D; note the logarithmic scale of these graphs). Two late endoderm markers $A F P$ and $A l b 1$ showed a similar increase of expression in mutant EBs (Fig. 6E and F). Expression levels of the trophoblast marker $C d x 2$, and the mesendoderm marker Gsc, were also up-regulated in mutant EBs while the neurectoderm marker Sox 1 was slightly decreased (Fig. 6G - I). Together, these data show that Foxd3 mutant EBs undergo spontaneous differentiation into the same repertoire of lineages that was demonstrated with mutant ES cells in the presence of LIF: mesendoderm and trophectoderm, not neuroectoderm.

\section{DISCUSSION}

\section{Foxd3 Maintains ES Cell Survival and Self-renewal while Repressing Differentiation}

ES cells are unique in their ability to remain self-renewing and pluripotent in vitro. These processes are tightly regulated by a network of transcription factors, only some of which are well understood ${ }^{31}$. Our results establish two intertwined roles for Foxd3 in ES cells: this protein is required to maintain ES cell survival and self-renewal, while simultaneously repressing differentiation into either normal differentiation pathways (endoderm and mesoderm) or abnormal ones (trophectoderm) (see model in Fig. 7). 
The role of Foxd3 regulating ES cell survival is in agreement with our in vivo studies demonstrating similar roles for Foxd3 in both early embryos ${ }^{11}$ and neural crest progenitors $^{13}$. Foxd $3^{-/-}$embryos exhibit increased programmed cell death at $6.5 \mathrm{dpc}$, and in vitro cultures of mutant blastocysts also contain more TUNEL-positive cells than wild type blastocyst cultures 11 . Deletion of Foxd3 in the neural crest, another multipotent cell lineage, resulted in considerable apoptosis of neural crest progenitor cells ${ }^{13}$. Our experiments here monitoring the expression of residual Foxd3 in treated cells together with TUNEL revealed very few, if any, double-positive cells, strongly suggesting a cell-autonomous function of Foxd3 in maintaining ES cell survival. Furthermore, our results show that Foxd3 mutant ES cells maintaining Oct 4 expression are protected from programmed cell death, whereas those mutant cells that have differentiated inappropriately (marked by Foxa2) have a much higher tendency to undergo apoptosis. These results suggest that the increased apoptosis in mutant ES cells could be a secondary consequence of abberant differentiation. However, our results do not rule out the possibility that Foxd3 may directly regulate genes in apoptotic pathways. Interestingly, the proliferation capacity of mutant ES cells is comparable to that of control cells even as their ability to self-renew is greatly decreased. Therefore, our results point to a specific function of Foxd3 in maintaining ES cell survival and self-renewal, without affecting proliferation.

The early lethality of Foxd3 mutant embryos makes it difficult to study the role of Foxd3 in regulating differentiation 11 . Our ES cell data presented here demonstrate up-regulation of multiple differentiation markers for several cell lineages in Foxd3 mutant ES cells and EBs, suggesting that Foxd3 may act as a gatekeeper in pluripotent ES cells to prevent cells from inappropriate differentiation, thereby maintaining the pool of stem cells. Similarly, in the trophoblast lineage, Foxd 3 controls differentiation of trophoblast stem cells in order to maintain a multipotent progenitor cell population ${ }^{12}$.

\section{Positioning Foxd3 in the Transcription Factor Network Regulating ES Cell Self-Renewal and Pluripotency}

Recent genome-wide studies suggest that Oct4, Sox 2 and Nanog form a regulatory feedback circuit to maintain self-renewal and pluripotency in ES cells 32,33 . These are not the only crucial factors, a parallel pathway involving transcription factors Esrrb and Tbx3 also represses differentiation to maintain ES cell self-renewal and pluripotency 22 . Expression of Oct4, Sox2 and/or Nanog in concert with Klf4, c-Myc and/or Lin-28 reprograms human or murine somatic cells from multiple sources to adopt stem cell behavior and generate iPSCs that share all the properties of ES cells ${ }^{6-10}$. In this study, we show that mRNA levels of Pou5f1, Sox2, Nanog, Esrrb, Tbx3, Klf4 and $c$-Myc are maintained or slightly up-regulated in Foxd3 mutant ES cells, suggesting that Foxd 3 acts downstream of, or in parallel with, these factors to regulate selfrenewal and inhibit spontaneous differentiation of ES cells. In fact, iPSCs induced by the expression of OCT4, SOX2, NANOG and LIN28 from human somatic cells ${ }^{10}$ express FOXD3 (Dr. James Thomson, personal communication), suggesting that FOXD3 could be one of the downstream executors to induce stem cell like properties in iPSCs.

\section{Context-Dependent Function of Foxd3 during Development}

Our results add to previous findings suggesting that Foxd3 is a multifunctional protein playing a role in many divergent processes in the embryo and in progenitor cells. As a transcription factor, Foxd3 has been shown to act either as a repressor or an activator depending upon the cellular context. During Xenopus mesoderm induction, FoxD3 functions as a repressor to induce mesoderm and elegant structure-function analyses identified a strong transcriptional repression domain in the $\mathrm{C}$ terminus of Xenopus FoxD 34,35 . Within this domain is a Groucho corepressor interaction motif conserved in Xenopus, zebrafish, chick and mammals. In Xenopus, Foxd3 binds DNA and recruits Grg4 (Groucho-related gene 4) to repress 
transcription ${ }^{35}$, likely by the recruitment of histone deacetylases that alter chromatin conformation and result in decreased transcription. It is unclear if mammalian Foxd3 functions in the same manner as Xenopus FoxD3; mammalian Foxd3 has several divergent sequence domains from either Xenopus or zebrafish FoxD3 which might suggest that these orthologs function by different mechanisms. Expression of the murine homologs of Grg 1-4, called Tle 1-4, have been implicated in a variety of embryonic functions including segmentation and neurogenesis (reviewed in Buscarlet and Stifani, 2007 and Gasperowicz and Otto, 2005) ${ }^{36}$, 37, but thus far a role for these proteins in ES cell pluripotency has not been examined. Embryonic expression of the murine Groucho homologs is widespread making it likely that other co-factors might also be relevant to the regulation of Foxd3 protein function in a context specific manner. Polycomb group $(\mathrm{PcG})$ transcriptional repressors repress many developmental regulatory genes in murine ES cells ${ }^{38}$. Because neither Groucho nor PcG proteins bind DNA directly, it is likely that they are recruited to target genes by sequencespecific DNA-binding transcription factors such as Foxd3.

In many circumstances Foxd3 acts as a repressor, but in other situations, Foxd3 has transcriptional activator activity. In the human embryonic kidney 293 cell line, ectopically expressed Foxd 3 activates expression of the endoderm genes Foxal and Foxa ${ }^{39}$. Other work demonstrated that Foxd3 activates expression of a reporter driven by either the Nanog or Pou5f1 promoter in ES cells, and ES cells transfected with siRNA for Foxd 3 have reduced expression of Nanog and Pou $5 \mathrm{fl}^{40}$. These results support an activator role for Foxd3 maintaining Pou5fl and Nanog expression, however, co-transfection of Foxd3 and a reporter preceded by multimers of a 30bp Foxd3 binding site from the Nanog promoter, Foxd 3 overexpression causes decreased expression of this reporter in a dose-dependent manner, suggesting that Foxd3 can act as a repressor in ES cells ${ }^{40}$. ES cells transfected with Foxd3 siRNA show reduced expression of Pou5f1 and Nanog, but the efficiency of the siRNA is unknown. Both Oct 4 and Sox 2 levels must be maintained in a very narrow window to maintain pluripotency of ES cells, and Oct4 and Nanog have a complex co-regulation with biphasic regulation of Nanog by Oct4, such that a steady-state concentration of Oct 4 maintains Nanog expression, while an elevated level of Oct4 represses Nanog mRNA levels ${ }^{40}$. Therefore, it is clear that the cross-regulation of these self-renewal factors is complex, and individual transcription factors may function as repressors or activators in the same cell type.

These proposed divergent mechanisms of action for Foxd3 as either a repressor or an activator could indicate a role for Foxd3 as a convergent point for multiple pathways. Other Fox proteins have been proposed to function as so-called "pioneer factors" to modify chromatin; FoxA1 binds the Albumin 1 enhancer prior to Alb1 transcription and this binding of FoxA1 appears to open the chromatin and allow access to other transcription factors 41,42 . Similar function has been ascribed to Foxe1 binding to the thyroperoxidase promoter and thereby opening chromatin ${ }^{43}$. It is possible that Foxd3 is acting at promoters of differentiation specific genes to allow access to other transcription factors that modulate transcription. In fact, this has been suggested by chromatin immunoprecipitation assays demonstrating that Foxd3 binds the inactive Albl promoter in ES cells and may modulate methylation of a $\mathrm{CpG}$ to control chromatin conformation ${ }^{44}$. This is supported by our data in Foxd3 mutant ES cells that along with other markers of endoderm development, $A l b l$ transcription is precociously increased in EBs and raises the possibility that Foxd3 may be acting at a key step in regulating multiple early lineage loci. Future work will be focused on identifying the molecular partners and targets of Foxd3 that function to carry out these essential roles in both ES cells and other multipotent precursors.

\section{Supplementary Material}

Refer to Web version on PubMed Central for supplementary material. 


\section{Acknowledgements}

The authors would like to thank Alison Dell for preliminary data on this project, Audrey Frist and Alison LeGrone for technical help. Thanks to Chin Chiang for the Foxa2 antibody, Larysa Pevny for the Sox2 antibody, Mark Magnuson's laboratory for use of their Real-Time PCR machine, and James Thomson and Ron Stewart for sharing unpublished data. Thanks also to Dan Kessler, Mark Magnuson, Nathan Mundell, Brian Nelms and Chris Wright for their thoughtful comments on the manuscript. This work was supported by a grant from NIH (HD36720) to PAL.

Funded by NIH grant HD36720 to P.A. Labosky

\section{References Cited}

1. Avilion AA, Nicolis SK, Pevny LH, Perez L, Vivian N, Lovell-Badge R. Multipotent cell lineages in early mouse development depend on SOX2 function. Genes Dev Jan 1;2003 17(1):126-140. [PubMed: 12514105]

2. Masui S, Nakatake Y, Toyooka Y, et al. Pluripotency governed by Sox2 via regulation of Oct3/4 expression in mouse embryonic stem cells. Nat Cell Biol Jun;2007 9(6):625-635. [PubMed: 17515932]

3. Nichols J, Zevnik B, Anastassiadis K, et al. Formation of pluripotent stem cells in the mammalian embryo depends on the POU transcription factor Oct4. Cell Oct 30;1998 95(3):379-391. [PubMed: 9814708]

4. Mitsui K, Tokuzawa Y, Itoh $\mathrm{H}$, et al. The homeoprotein Nanog is required for maintenance of pluripotency in mouse epiblast and ES cells. Cell May 30;2003 113(5):631-642. [PubMed: 12787504]

5. Chambers I, Colby D, Robertson M, et al. Functional expression cloning of Nanog, a pluripotency sustaining factor in embryonic stem cells. Cell May 30;2003 113(5):643-655. [PubMed: 12787505]

6. Maherali N, Sridharan R, Xie W, et al. Directly reprogrammed fibroblasts show global epigenetic remodeling and widespread tissue contribution. Cell Stem Cell 2007;1:55-70. [PubMed: 18371336]

7. Okita K, Ichisaka T, Yamanaka S. Generation of germline-competent induced pluripotent stem cells. Nature Jul 19;2007 448(7151):313-317. [PubMed: 17554338]

8. Takahashi K, Yamanaka S. Induction of pluripotent stem cells from mouse embryonic and adult fibroblast cultures by defined factors. Cell Aug 25;2006 126(4):663-676. [PubMed: 16904174]

9. Wernig M, Meissner A, Foreman R, et al. In vitro reprogramming of fibroblasts into a pluripotent EScell-like state. Nature Jul 19;2007 448(7151):318-324. [PubMed: 17554336]

10. Yu J, Vodyanik MA, Smuga-Otto K, et al. Induced pluripotent stem cell lines derived from human somatic cells. Science Dec 21;2007 318(5858):1917-1920. [PubMed: 18029452]

11. Hanna LA, Foreman RK, Tarasenko IA, Kessler DS, Labosky PA. Requirement for Foxd3 in maintaining pluripotent cells of the early mouse embryo. Genes Dev Oct 15;2002 16(20):2650-2661. [PubMed: 12381664]

12. Tompers DM, Foreman RK, Wang Q, Kumanova M, Labosky PA. Foxd3 is required in the trophoblast progenitor cell lineage of the mouse embryo. Dev Biol Sep 1;2005 285(1):126-137. [PubMed: 16039639]

13. Teng L, Mundell NA, Frist AY, Wang Q, Labosky PA. Requirement for Foxd3 in maintenance of neural crest progenitors. Development 2008;135:1615-1624. [PubMed: 18367558]

14. Sutton J, Costa R, Klug M, et al. Genesis, a winged helix transcriptional repressor with expression restricted to embryonic stem cells. J Biol Chem Sep 20;1996 271(38):23126-23133. [PubMed: 8798505]

15. Hayashi S, McMahon AP. Efficient recombination in diverse tissues by a tamoxifen-inducible form of Cre: a tool for temporally regulated gene activation/inactivation in the mouse. Dev Biol Apr 15;2002 244(2):305-318. [PubMed: 11944939]

16. Buehr M, Smith A. Genesis of embryonic stem cells. Philos Trans R Soc Lond B Biol Sci Aug 29;2003 358(1436):1397-1402. [PubMed: 14511487]discussion 1402

17. Nagy A, Gertsenstein M, Vintersten K, Behringer R. Manipulating the mouse embryo: A laboratory manual (Third Edition ed). 2003

18. Galan-Caridad JM, Harel S, Arenzana TL, et al. Zfx controls the self-renewal of embryonic and hematopoietic stem cells. Cell Apr 20;2007 129(2):345-357. [PubMed: 17448993] 
19. Ying QL, Nichols J, Chambers I, Smith A. BMP induction of Id proteins suppresses differentiation and sustains embryonic stem cell self-renewal in collaboration with STAT3. Cell Oct 31;2003 115 (3):281-292. [PubMed: 14636556]

20. Zhang J, Tam WL, Tong GQ, et al. Sall4 modulates embryonic stem cell pluripotency and early embryonic development by the transcriptional regulation of Pou5f1. Nat Cell Biol Oct;2006 8(10): 1114-1123. [PubMed: 16980957]

21. Niwa H. How is pluripotency determined and maintained? Development Feb;2007 134(4):635-646. [PubMed: 17215298]

22. Ivanova N, Dobrin R, Lu R, et al. Dissecting self-renewal in stem cells with RNA interference. Nature Aug 3;2006 442(7102):533-538. [PubMed: 16767105]

23. Meissner A, Wernig M, Jaenisch R. Direct reprogramming of genetically unmodified fibroblasts into pluripotent stem cells. Nat Biotechnol Oct;2007 25(10):1177-1181. [PubMed: 17724450]

24. Beddington RS, Robertson EJ. An assessment of the developmental potential of embryonic stem cells in the midgestation mouse embryo. Development Apr;1989 105(4):733-737. [PubMed: 2598811]

25. Rathjen J, Lake JA, Bettess MD, Washington JM, Chapman G, Rathjen PD. Formation of a primitive ectoderm like cell population, EPL cells, from ES cells in response to biologically derived factors. J Cell Sci Mar;1999 112(Pt 5):601-612. [PubMed: 9973595]

26. Keller G. Embryonic stem cell differentiation: emergence of a new era in biology and medicine. Genes Dev May 15;2005 19(10):1129-1155. [PubMed: 15905405]

27. Martin GR. Isolation of a pluripotent cell line from early mouse embryos cultured in medium conditioned by teratocarcinoma stem cells. Proc Natl Acad Sci U S A Dec;1981 78(12):7634-7638. [PubMed: 6950406]

28. Evans MJ, Kaufman MH. Establishment in culture of pluripotential cells from mouse embryos. Nature Jul 9;1981 292(5819):154-156. [PubMed: 7242681]

29. Martin GR, Evans MJ. Differentiation of clonal lines of teratocarcinoma cells: formation of embryoid bodies in vitro. Proc Natl Acad Sci U S A Apr;1975 72(4):1441-1445. [PubMed: 1055416]

30. Coucouvanis E, Martin GR. Signals for death and survival: a two-step mechanism for cavitation in the vertebrate embryo. Cell Oct 20;1995 83(2):279-287. [PubMed: 7585945]

31. Pan G, Thomson JA. Nanog and transcriptional networks in embryonic stem cell pluripotency. Cell Res Jan;2007 17(1):42-49. [PubMed: 17211451]

32. Boyer LA, Lee TI, Cole MF, et al. Core transcriptional regulatory circuitry in human embryonic stem cells. Cell Sep 23;2005 122(6):947-956. [PubMed: 16153702]

33. Loh YH, Wu Q, Chew JL, et al. The Oct4 and Nanog transcription network regulates pluripotency in mouse embryonic stem cells. Nat Genet Apr;2006 38(4):431-440. [PubMed: 16518401]

34. Steiner AB, Engleka MJ, Lu Q, et al. FoxD3 regulation of Nodal in the Spemann organizer is essential for Xenopus dorsal mesoderm development. Development Dec;2006 133(24):4827-4838. [PubMed: 17092955]

35. Yaklichkin S, Steiner AB, Lu Q, Kessler DS. FoxD3 and Grg4 physically interact to repress transcription and induce mesoderm in Xenopus. J Biol Chem Jan 26;2007 282(4):2548-2557. [PubMed: 17138566]

36. Buscarlet M, Stifani S. The 'Marx' of Groucho on development and disease. Trends Cell Biol Jul; 2007 17(7):353-361. [PubMed: 17643306]

37. Gasperowicz M, Otto F. Mammalian Groucho homologs: redundancy or specificity? J Cell Biochem Jul 1;2005 95(4):670-687. [PubMed: 15861397]

38. Boyer LA, Plath K, Zeitlinger J, et al. Polycomb complexes repress developmental regulators in murine embryonic stem cells. Nature May 18;2006 441(7091):349-353. [PubMed: 16625203]

39. Guo Y, Costa R, Ramsey H, et al. The embryonic stem cell transcription factors Oct-4 and FoxD3 interact to regulate endodermal-specific promoter expression. Proc Natl Acad Sci U S A Mar 19;2002 99(6):3663-3667. [PubMed: 11891324]

40. Pan G, Li J, Zhou Y, Zheng H, Pei D. A negative feedback loop of transcription factors that controls stem cell pluripotency and self-renewal. Faseb J Aug;2006 20(10):1730-1732. [PubMed: 16790525] 
41. Cirillo LA, Lin FR, Cuesta I, Friedman D, Jarnik M, Zaret KS. Opening of compacted chromatin by early developmental transcription factors HNF3 (FoxA) and GATA-4. Mol Cell Feb;2002 9(2):279289. [PubMed: 11864602]

42. Gualdi R, Bossard P, Zheng M, Hamada Y, Coleman JR, Zaret KS. Hepatic specification of the gut endoderm in vitro: cell signaling and transcriptional control. Genes Dev Jul 1;1996 10(13):16701682. [PubMed: 8682297]

43. Cuesta I, Zaret KS, Santisteban P. The forkhead factor FoxE1 binds to the thyroperoxidase promoter during thyroid cell differentiation and modifies compacted chromatin structure. Mol Cell Biol Oct; 2007 27(20):7302-7314. [PubMed: 17709379]

44. Xu J, Pope SD, Jazirehi AR, et al. Pioneer factor interactions and unmethylated CpG dinucleotides mark silent tissue-specific enhancers in embryonic stem cells. Proc Natl Acad Sci U S A Jul 24;2007 104(30):12377-12382. [PubMed: 17640912] 
A

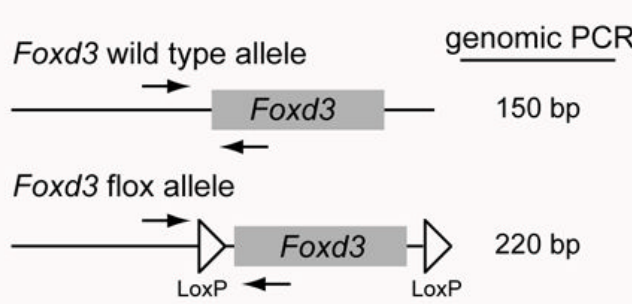

B

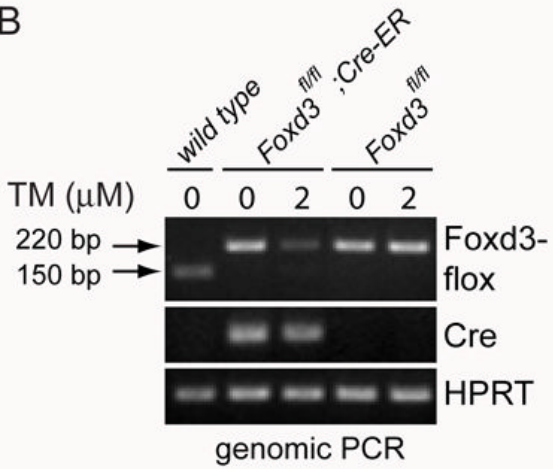

genomic PCR

Recombined allele

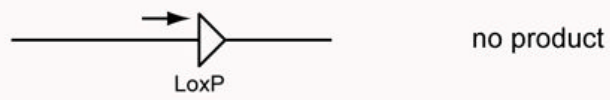

C

\begin{tabular}{|c|c|c|c|}
\hline Foxd $3^{\text {f }}$ & Cre-ER & & \\
\hline E1 & E2 & C1 & $\mathrm{C} 2$ \\
\hline 02 & 02 & 0 & 0 \\
\hline
\end{tabular}

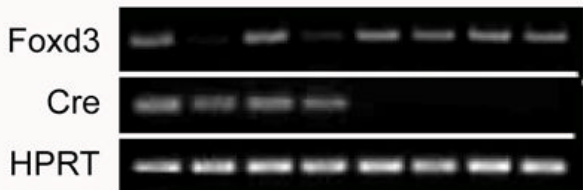

RT-PCR

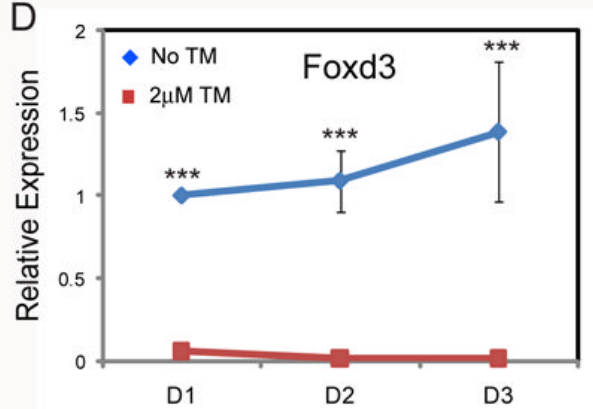

E
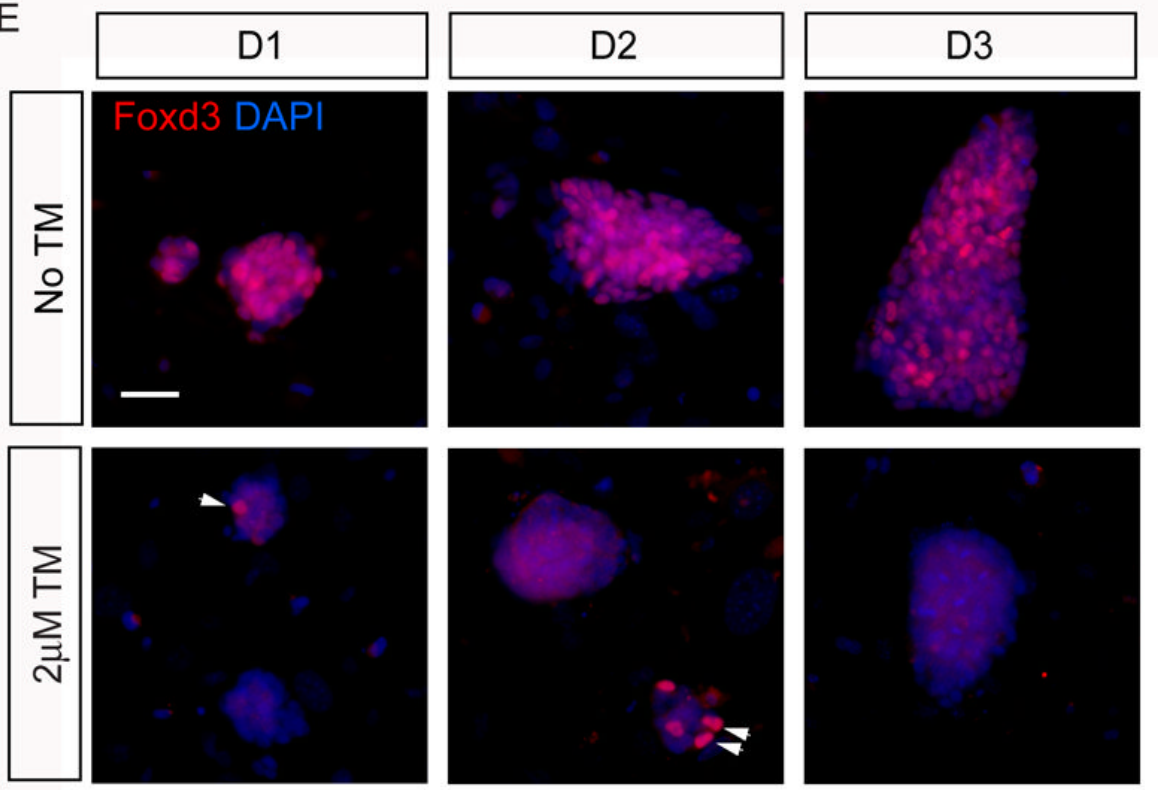

Figure 1. Tamoxifen treatment induces efficient deletion of Foxd 3

(A): Diagram of the Foxd3 wild type, conditional ("floxed") and recombined alleles. Arrows indicate PCR primers that flank the 5' LoxP site. (B): Genomic DNA PCR of wild type ES cells, Foxd $3^{\text {fllfli }}$; Cre-ER and Foxd $3^{f l / f l} \mathrm{ES}$ cells cultured in the presence or absence of $2 \mu \mathrm{M}$ TM for 3 days using flox and Cre primers. HPRT serves as an internal control. (C): Foxd3, Cre and Hprt RT-PCR of cDNA from multiple lines of ES cells treated with or without $2 \mu \mathrm{M}$ TM for 3 days. (D): qRT-PCR showing significant reduction of Foxd 3 mRNA in Foxd $3^{f l f l}$; $C r e-$ ER ES cells treated with $2 \mu \mathrm{M}$ TM. Levels of Foxd 3 transcript are compared by Student's t-test (***: p<0.001). (E): Immunocytochemistry of Foxd3 (red) and DAPI (blue) showing absence 
of nuclear Foxd3 in most TM-treated Foxd $3^{f l f f}$; Cre-ER ES cells with rare retention of Foxd3 in the nuclei of some cells (arrowheads). Scale bar: $50 \mu \mathrm{m}$. 

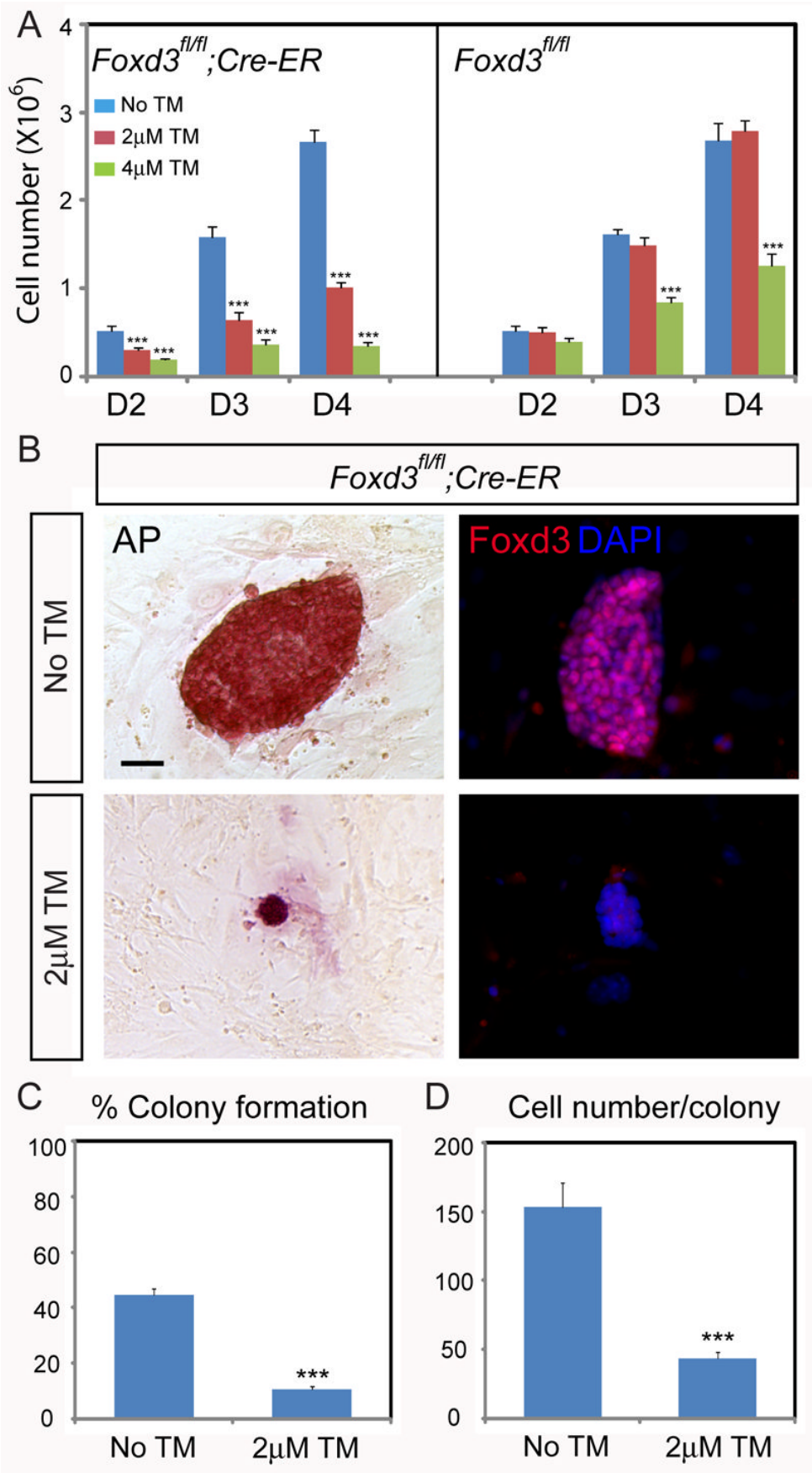

Figure 2. Defective self-renewal of Foxd3 mutant ES cells

(A): Cell number analysis of Foxd $3^{f l / f l}$; Cre-ER cell lines and Foxd $3^{f l / f l}$ control cell lines treated with 0,2 or $4 \mu \mathrm{M}$ TM. Surviving cells were counted with a hemocytometer after 2, 3 and 4 days of TM treatment. (B): Alkaline phosphatase staining and Foxd3 immunolocalization in colonies generated from the self-renewal analysis of Foxd $3^{f l f l}$; Cre-ER cell lines. Scale bar: $50 \mu \mathrm{m}$. (C): Colony formation efficiency as shown by the number of AP-positive colonies normalized against total number of cells plated. (D): Number of cells per colony in control and mutant self-renewal cultures.

Data shown are Mean \pm SEM $(* * * \mathrm{p}<0.001)$. 
A
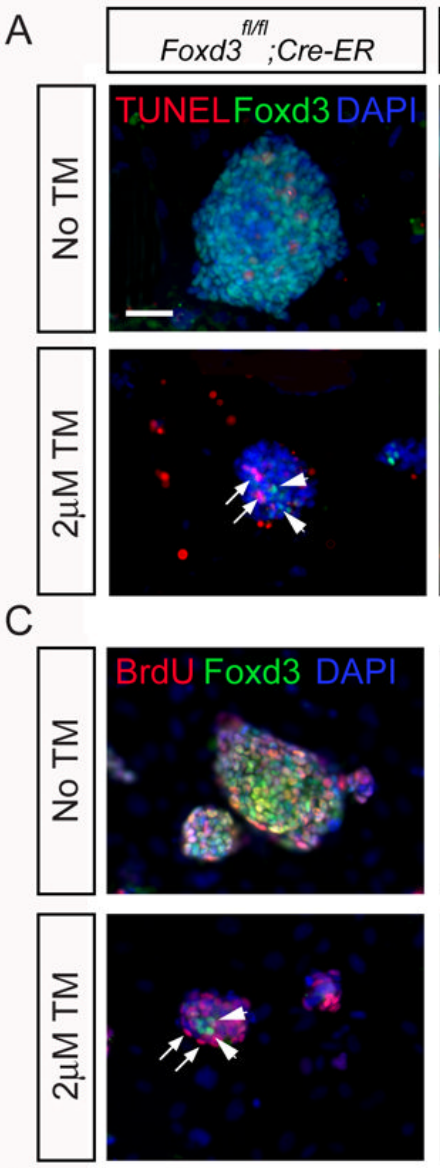

E
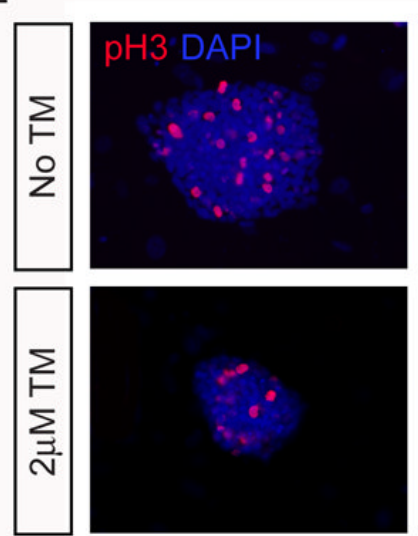
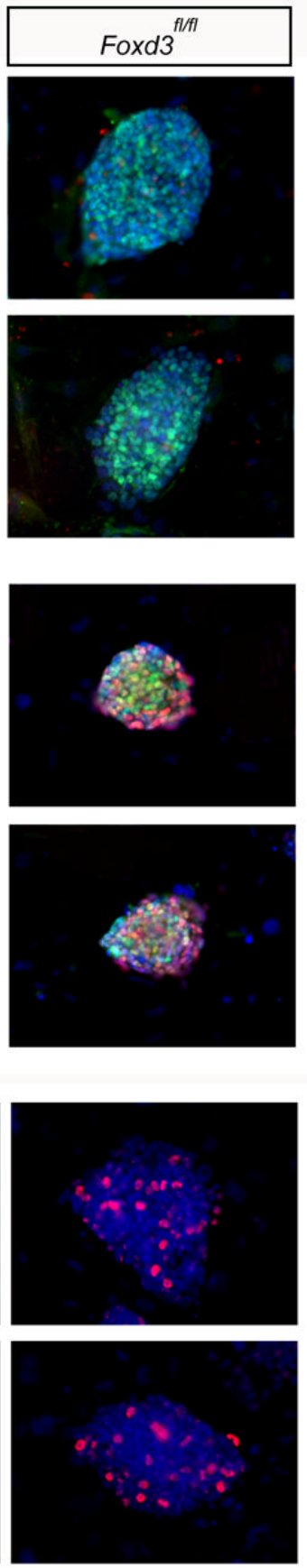

B
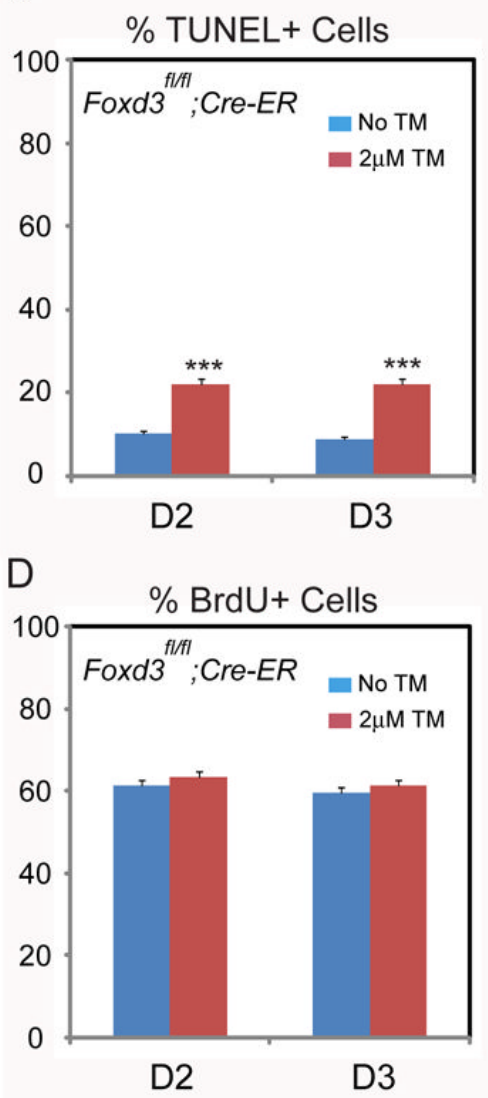

F

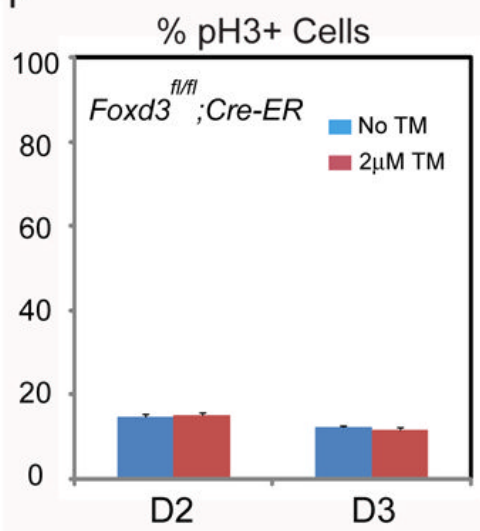

Figure 3. Foxd3 is required for ES cell survival

(A): TUNEL labeling (red) and Foxd3 staining (green) of Foxd $3^{f l f f l}$; Cre-ER and Foxd $3^{f l / f l}$ cell lines with or without $2 \mu \mathrm{M}$ TM treatment revealing increased apoptosis of Foxd3-deficient ES cells (arrows). (B): Quantification of TUNEL-positive cells normalized against total number of DAPI-stained cells in Foxd $3^{f l f l}$; $C r e-E R$ cultures after 2 or 3 days of TM treatment. (C): BrdU incorporation as a measure of cells in S phase (red) and Foxd3 (green) staining. Many Foxd3-deficient ES cells are BrdU-positive (arrows). (D): Quantification of percentage of BrdU-positive cells in Foxd $3^{f l f f l}$; Cre-ER cell cultures. (E): Phospho-histone H3 (red) staining for cells in G2-M phase. (F): Quantification of percentage of pH3-positive cells in Foxd3flffl; Cre-ER cell cultures. ES cells in (A), (C) and (E) were counter-stained with DAPI (blue). 
Arrowheads in (A) and (C) point to a few Foxd3-positive cells in mutant cultures. Scale bar: $50 \mu \mathrm{m}$. Data in (B), (D) and (F) were obtained from three independent experiments with more than 7000 DAPI-positive cells counted for each treatment, and are shown as Mean \pm SEM (*** $\mathrm{p}<0.001)$. 
A
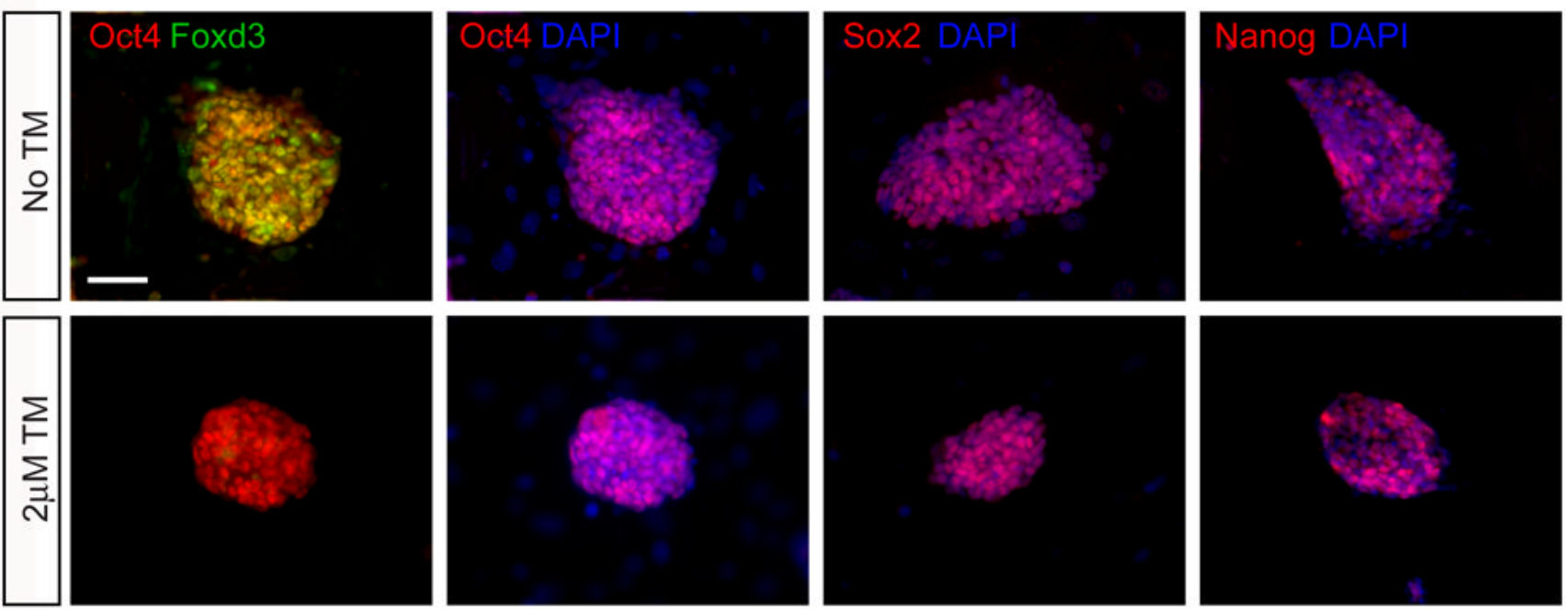

B
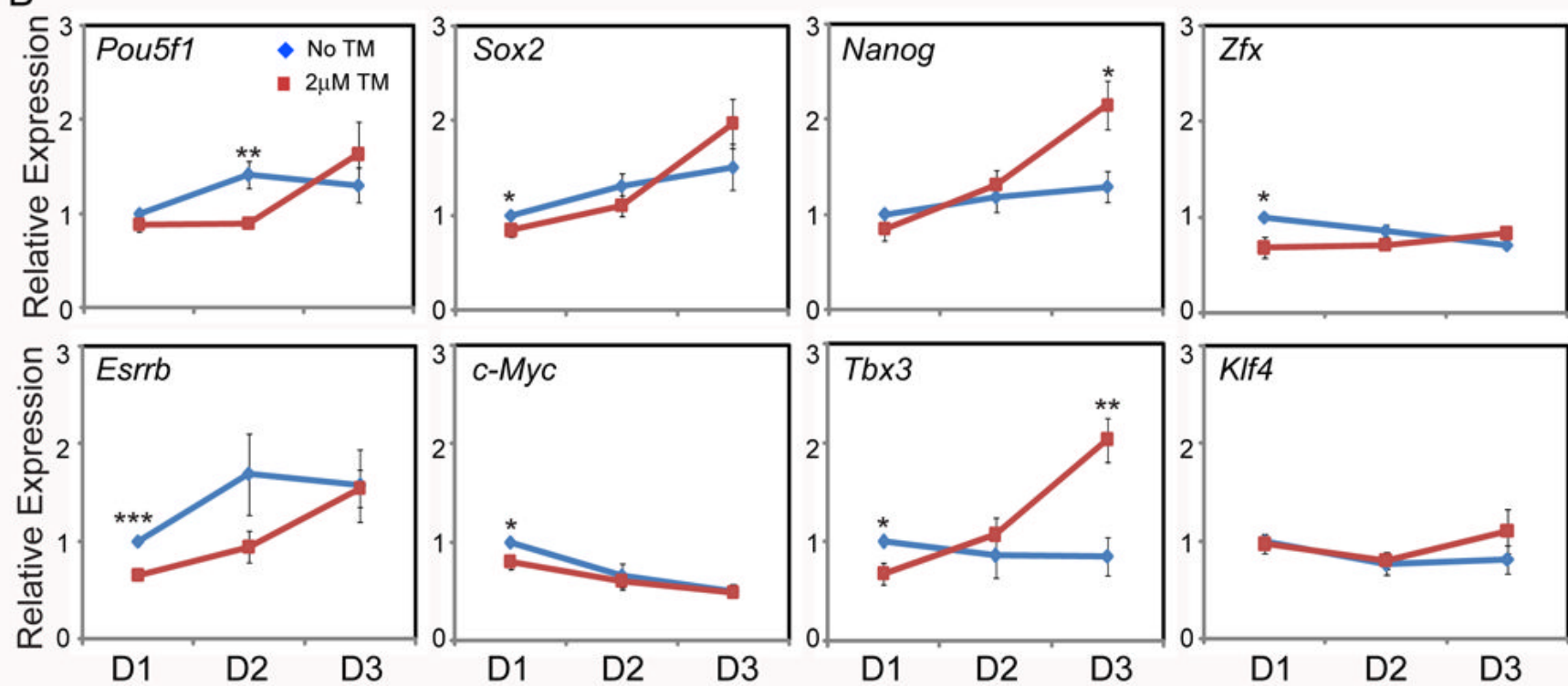

Figure 4. Foxd3 is not required for the expression of stem cell markers

(A): Immunocytochemistry shows nuclear staining of Oct4, Sox 2 and Nanog (red) in Foxd $3^{f l / f l}$; Cre-ER ES cells with or without $2 \mu \mathrm{M}$ TM treatment for 3 days. ES cells were counter-stained with DAPI (blue). Oct4 (red) and Foxd3 (green) double staining (leftmost panel) reveals that most Foxd3-deficient ES cells are Oct4-positive in mutant cultures and very little Foxd3 protein is observed in treated cells. Scale bar: $50 \mu \mathrm{m}$. (B): qRT-PCR analysis of stem cell marker gene expression in $2 \mu \mathrm{M}$ TM (red line) or no TM (blue line) treated cells for 1-3 days. mRNA levels of each gene are compared between control and TM-treated cells by Student's t-test $(* * *: \mathrm{p}<0.001 ; * * \mathrm{p}<0.01 ; * \mathrm{p}<0.05)$. 
A
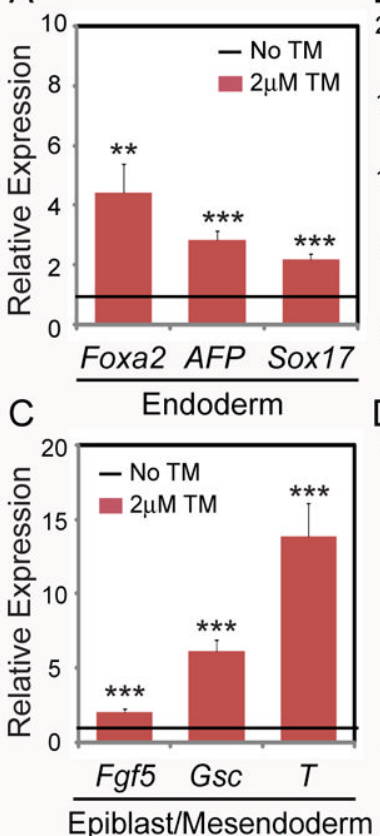

B

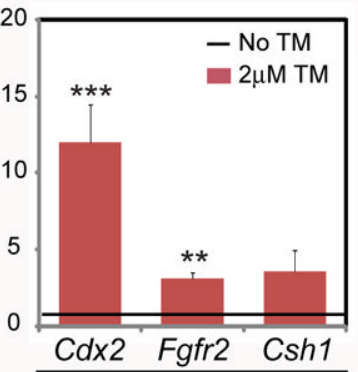

$\mathrm{D}$

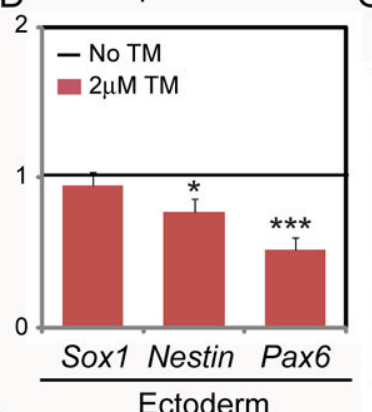

$\mathrm{E}$

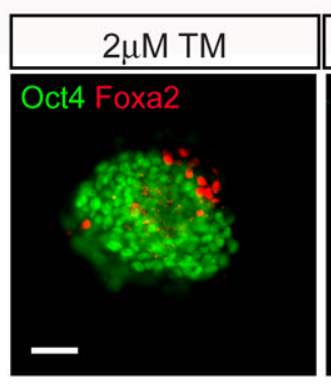

G
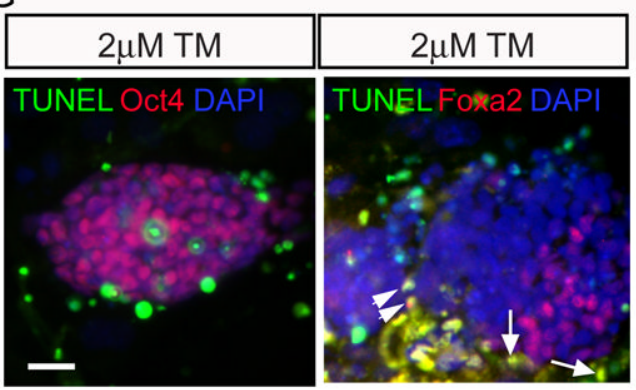

$\mathrm{F}$

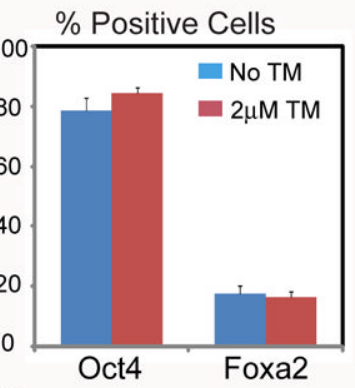

$\mathrm{H}$
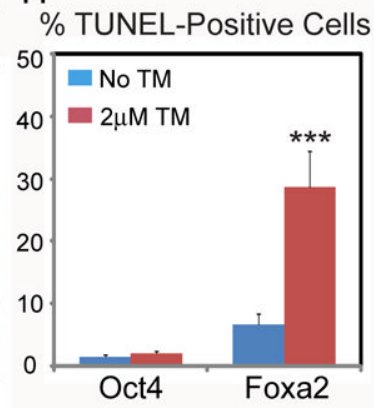

Figure 5. Foxd3 represses ES cell differentiation towards multiple lineages

(A): qRT-PCR analysis of transcript levels of primitive endoderm markers Foxa2, AFP and Sox17 in ES cells cultured with or without TM for 3 days. Bars represent transcript levels for each gene in $2 \mu \mathrm{M} \mathrm{TM}$ treated cells, and horizontal lines indicate the mRNA levels in untreated ES cells arbitrarily designated as 1. (B): qRT-PCR analysis of mRNA levels of trophectoderm markers $C d x 2, F g f r 2$ and $C s h 1 / P L 1$. (C): qRT-PCR analysis of mRNA levels of epiblast marker $F g f 5$, mesendoderm markers $T$ and $G s c$. (D): qRT-PCR analysis of neurectoderm markers Sox1 Nestin, and Pax6. (E): Immunocytochemistry of Foxa2 (red) and either Sox 2 or Oct4 (green) in Foxd $3^{f l f l}$; Cre-ER ES cells treated with $2 \mu \mathrm{M}$ TM for 3 days. Arrowheads: Sox2/Foxa2 double-positive cells. Scale bar: $50 \mu \mathrm{m}$. (F): Percent of Oct4- or Foxa2-positive cells in control and $2 \mu \mathrm{M}$ TM-treated cultures. Data were collected from three independent experiments, and $>2000$ cells were counted for each treatment group. (G): TUNEL labeling (green) and immunocytochemistry for either Oct 4 or Foxa2 (red) in Foxd $3^{f l f l}$; Cre-ER ES cells treated with $2 \mu \mathrm{M}$ TM for 3 days. Arrowheads: TUNEL/Foxa2 double-positive cells that are also DAPI-positive. Arrows: TUNEL/Foxa2 double-positive cells that are DAPI-negative indicating they have lost their nuclear integrity. Scale bar: $25 \mu \mathrm{m}$. (H): Percent of TUNELpositive cells in Oct4-positive or Foxa2-positive populations in control and mutant cultures. More than 2000 cells were counted for each treatment group. Data shown are Mean $\pm \operatorname{SEM}(* * *$ $\mathrm{p}<0.001 ; * * \mathrm{p}<0.01 ; * \mathrm{p}<0.05)$. 

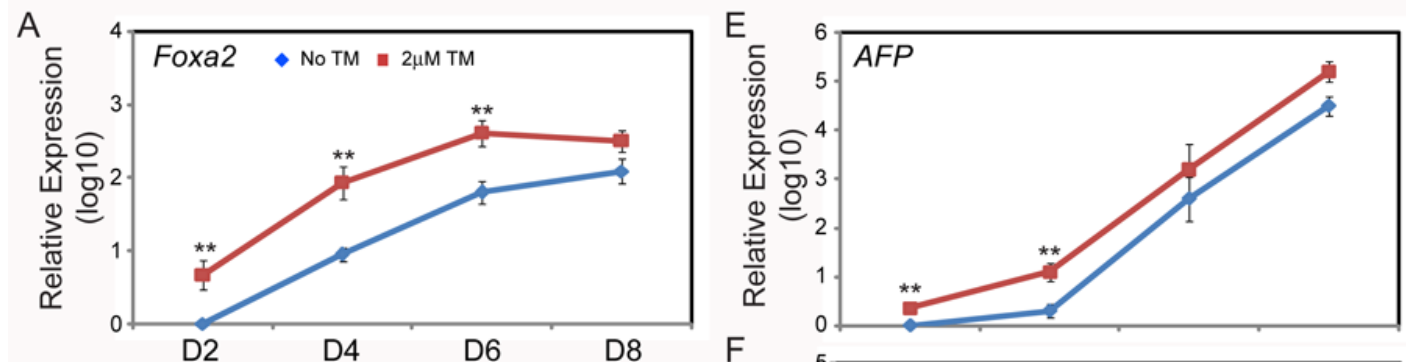

B
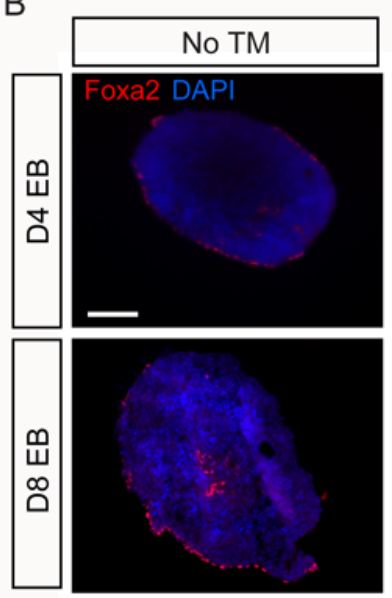

C
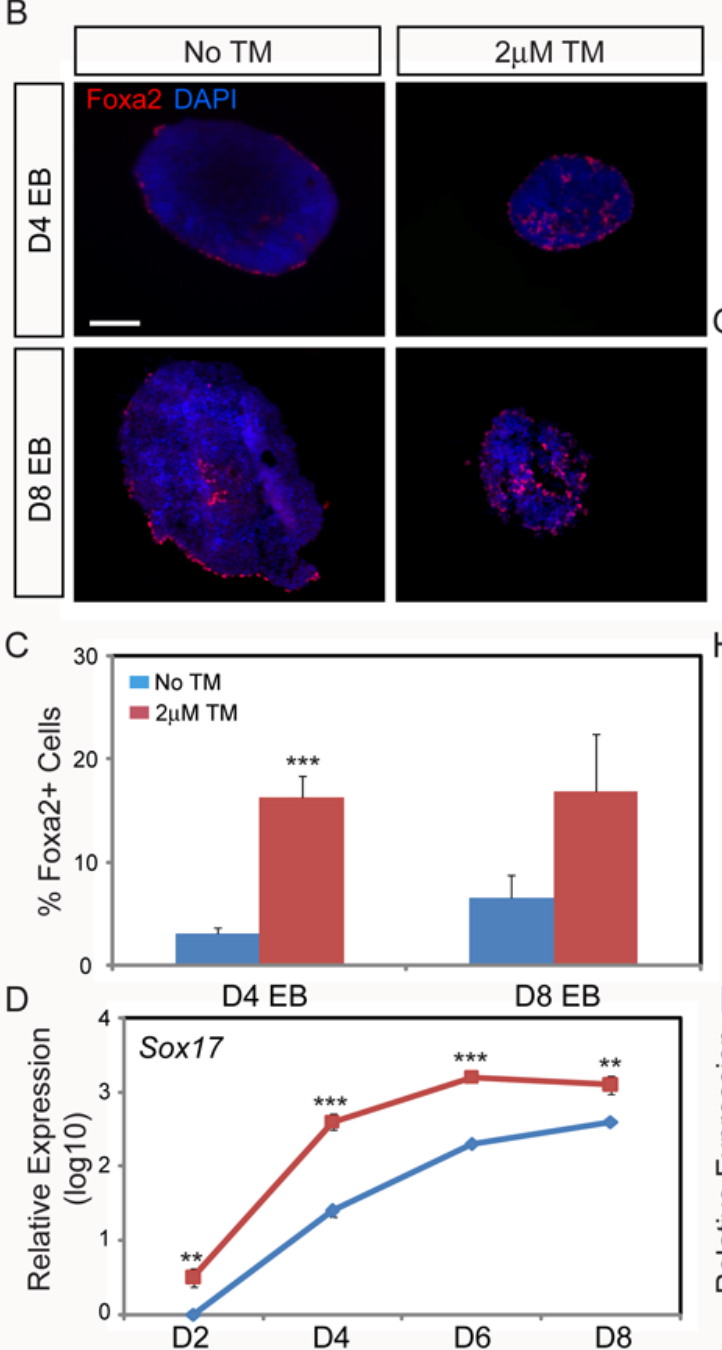
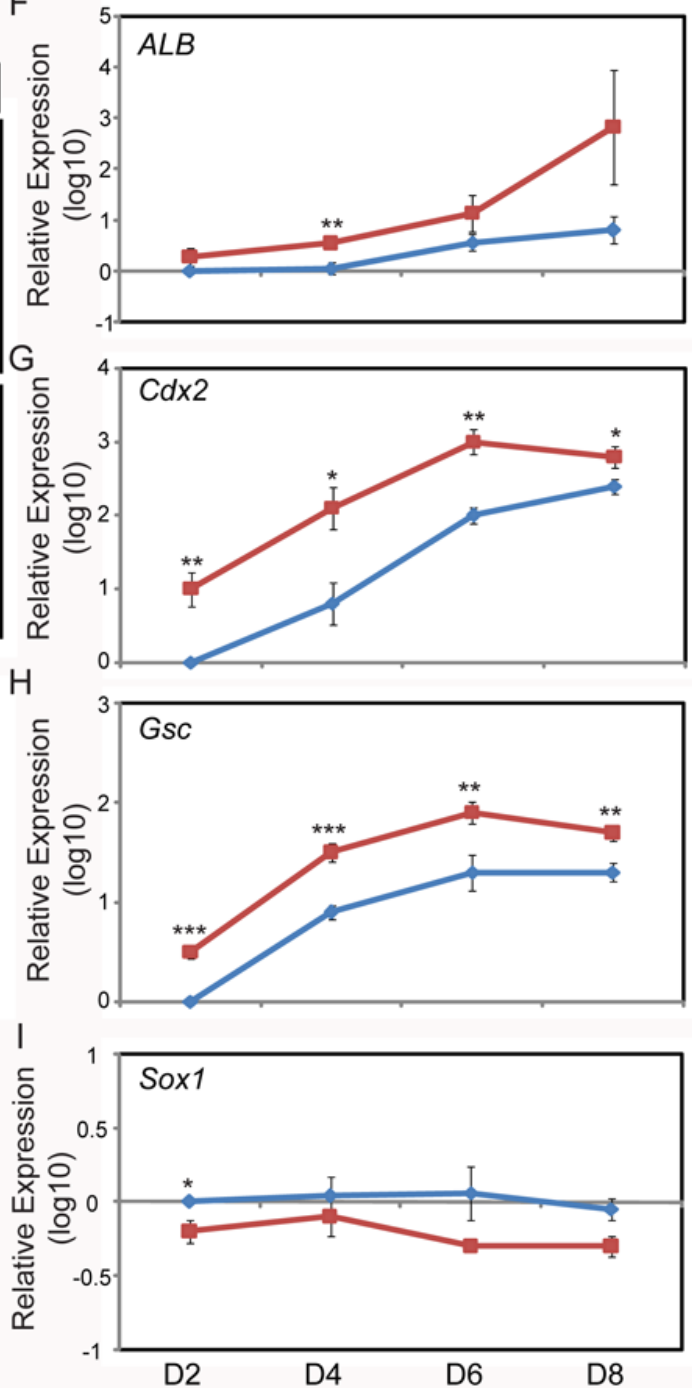

Figure 6. Increased differentiation of Foxd3 mutant EBs

(A): qRT-PCR analysis of endoderm marker Foxa2 mRNA levels in D2-D8 EBs cultured in the presence (red) or absence (blue) of $2 \mu \mathrm{M}$ TM. (B): Sections of untreated and TM-treated D4 and D8 EBs that have undergone whole mount immunocychemistry for Foxa2 (red) and counter-staining with DAPI (blue). Scale bar: $100 \mu \mathrm{m}$. (C): Percent of Foxa2-positive cells in D4 and D8 EBs. (D-I): qRT-PCR analysis of transcript levels of endoderm markers Sox17, $A F P$ and $A l b 1$, trophectoderm marker $C d x 2$, mesendoderm marker Gsc and neurectoderm marker Sox1 in D2-D8 EBs. Graphs in (A), (C)-(I) were plotted in logarithmic scale. mRNA levels of each gene are compared between control and TM-treated cells at each stage by Student's t-test. Data shown are Mean \pm SEM $(* * * \mathrm{p}<0.001 ; * * \mathrm{p}<0.01 ; * \mathrm{p}<0.05)$. 


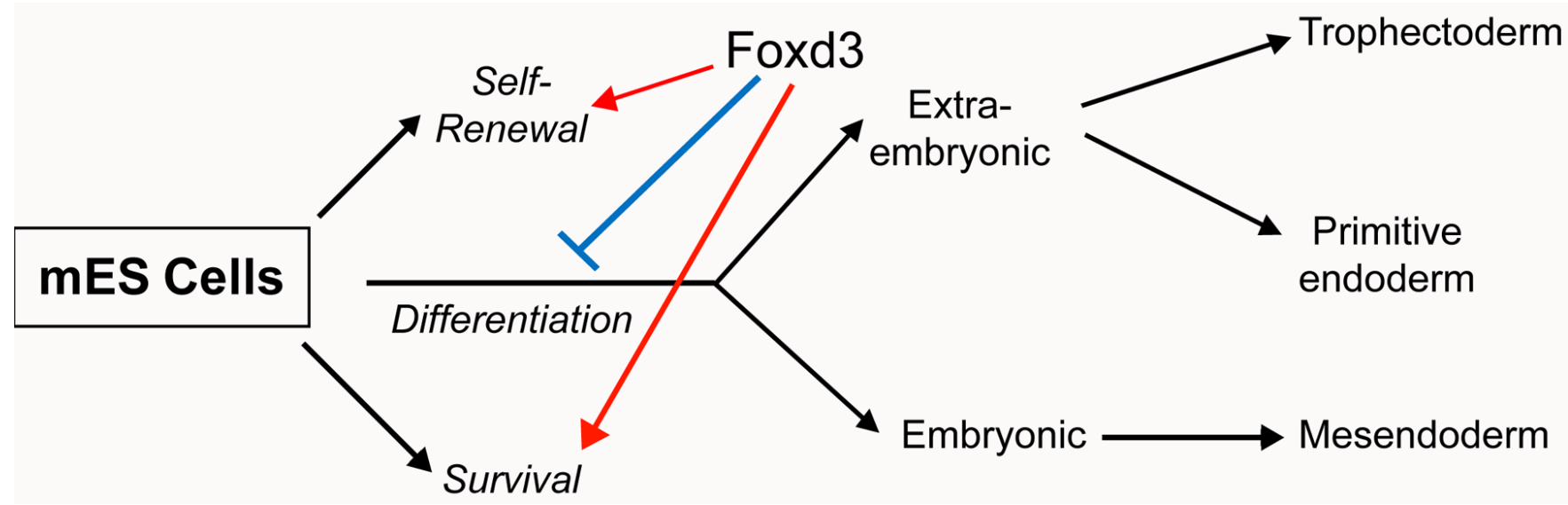

Figure 7. Model of Foxd3 functions in murine ES cells

Data presented here suggest a role for Foxd3 in maintenance of ES cell self-renewal and survival, and inhibition of differentiation into multiple lineages. 